\title{
Laparoscopic pyloroplasty for perforated peptic ulcer
}

\author{
Edvard Grišin ${ }^{1}$, Saulius Mikalauskas², Tomas Poškus², Valdemaras Jotautas², Kęstutis Strupas² \\ ${ }^{1}$ Clinic of Gastroenterology, Nephrourology and Surgery, Faculty of Medicine, Vilnius University, Vilnius, Lithuania \\ ${ }^{2}$ Centre of Abdominal Surgery, Vilnius University Hospital Santariskiu Klinikos, Vilnius, Lithuania
}

Videosurgery Miniinv 2017; 12 (3): 311-314

DOI: https://doi.org/10.5114/wiitm.2017.68537

\begin{abstract}
Peptic ulcer is a common disease affecting millions of people every year. Despite improved understanding and treatment of the disease, the number of patients admitted with duodenal peptic ulcer perforation has not decreased. Deaths from peptic ulcer disease overcome other common emergency situations. Laparoscopic repair of the perforated peptic ulcer (PPU) is the gold standard approach for simple perforation. However, in patients with large perforated chronic ulcers laparotomy with pyloroplasty is the standard treatment. It is generally accepted to perform open surgery in PPU emergencies because of the greater knowledge and experience gathered over the past decades and less potential harm for the patient or surgical complications. We present a case of successful laparoscopic pyloroplasty of a perforated duodenal ulcer with stenosis.
\end{abstract}

Key words: laparoscopic surgery, emergency surgery, perforated peptic ulcer.

\section{Introduction}

Duodenal peptic ulcer is a common disease affecting 4.5 million people every year in the United States. Even though the incidence of duodenal ulcer has decreased during the past decades, hospitalization rates have remained stable due to aging society and the impact of Helicobacter pylori and nonsteroidal anti-inflammatory drugs (NSAIDs). According to an analysis of 40 trials, the most common locations for ulcer are the duodenal bulb, pyloric region and gastric body [1]. The most common sign of perforation is pain in the epigastrium. Other important symptoms are anemia, bleeding, vomiting, and dysphagia [2]. The diagnostic algorithm is based on 3 stages: 1 ) upright chest X-ray (CXR) for acute abdominal pain and suspected perforation; 2) if CXR is negative a computed tomography (CT) scan is suggested, as it is sensitive to detect intra-abdominal free air; 3 ) if the CT scan did not provide enough information, a nasogastric tube is recommended [3]. Standard treatment of duodenal ulcer perforation involves patch repair (Graham patch) or omentopexy [4]. Besides these two methods, different laparoscopic techniques are also being tested. However, it is still open to debate whether the laparoscopic approach or open surgery is safer and the proper choice of treatment. If the ulcer presents with duodenal stenosis, open pyloroplasty is the treatment of choice.

We present a case of successful laparoscopic pyloroplasty for perforated duodenal ulcer with stenosis.

\section{Case report}

A 71-year-old woman presented to the emergency room with a 6-hour history of severe epigastric pain. After examination by a local general practitioner (GP) in her hometown, perforation of the duodenal ulcer was suspected and the patient was admitted to our hospital. She was diagnosed with duodenal ulcer 2 years ago, and was taking aspirin $100 \mathrm{mg}$ tablets for cardiovascular prophylaxis. On

\section{Address for correspondence}

Edvard Grišin, Clinic of Gastroenterology, Nephrourology and Surgery, Faculty of Medicine, Vilnius University, M. K. Čiurlionio g. 21,

03101 Vilnius, Lithuania, phone: +37 060295117, e-mail: edvard.grisin@gmail.com 


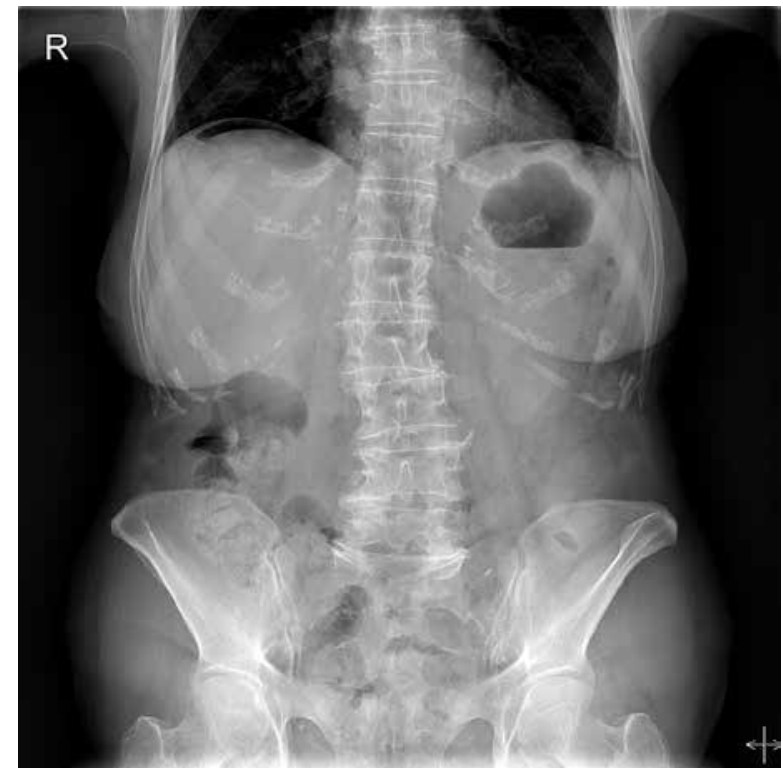

Photo 1. Plain upright X-ray examination of the abdomen indicating gas under the diaphragm

physical examination her heart rate was $60 \mathrm{bpm}$ and blood pressure was 130/60 mm Hg. Abdominal examination revealed severe pain in the area of the epigastrium with muscle guarding. She had leukocytosis of $15 \times 10^{9} / \mathrm{l}$ and C-reactive protein of $34.9 \mathrm{mg} / \mathrm{l}$. Chest X-ray examination of the abdomen revealed gas under the diaphragm (Photo 1). Perforated ulcer was diagnosed and urgent surgery was performed. Diagnostic laparoscopy showed perforated ulcer on the lesser curvature of the duodenal bulb with large fibrotic edges of the ulcer, forming duodenal stenosis. After ulcer excision, a large pyloroduodenal defect was visible (Photo 2). The defect was closed with interrupted Vicryl sutures, thus closing

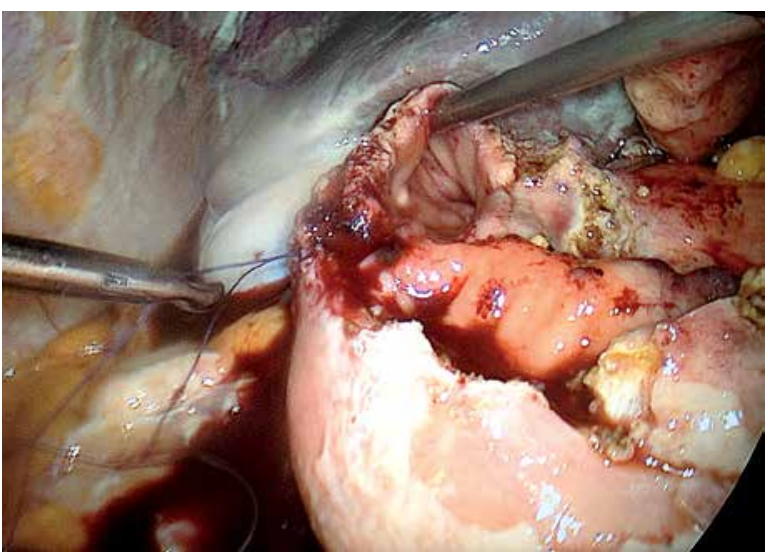

Photo 2. Pyloroduodenal defect after excision of the ulcer and scar tissue the pyloroplasty (Photo 3). Surgery was performed without any complications. A Gastrografin study was performed to rule out anastomotic leak on postoperative day (POD) 5 and was normal (Photos 4 A, B). The patient was discharged on POD 6 with the recommendation for omeprazole treatment and endoscopic surveillance. The pathology report showed fibrotic ulcerated tissue of the duodenal ulcer without evidence of $H$. pylori infection.

\section{Discussion}

We present a case of successful laparoscopic pyloroplasty for perforated duodenal ulcer with stenosis. We would like to highlight the possibilities of laparoscopic techniques in emergency situations, where urgent decisions should be taken immediately. We believe that pyloroplasty in the emergency setting can be safely performed through a laparoscopic approach, assuming there is the necessary experience in laparoscopic suturing. As it is only a case report study, further examinations and studies should be performed to approve the use of minimally invasive techniques in closing perforated peptic ulcer (PPU).

To the best of our knowledge, this is only the second case report of laparoscopic technique implementation in emergency settings. A previous publication in 2016 mentioned the possible shortterm advantages of a laparoscopic approach sealing a perforated peptic ulcer. Nonetheless, proper operative skills and techniques are necessary to fulfill all possible positive outcomes of laparoscopy over the open surgery approach [5].

Deaths from peptic ulcer disease overcome other common emergency situations. The incidence

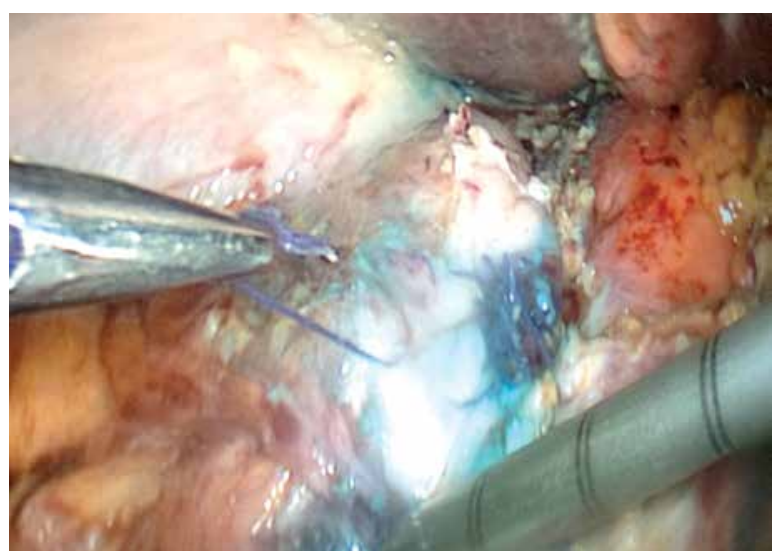

Photo 3. Closed defect with interrupted Vicryl sutures 

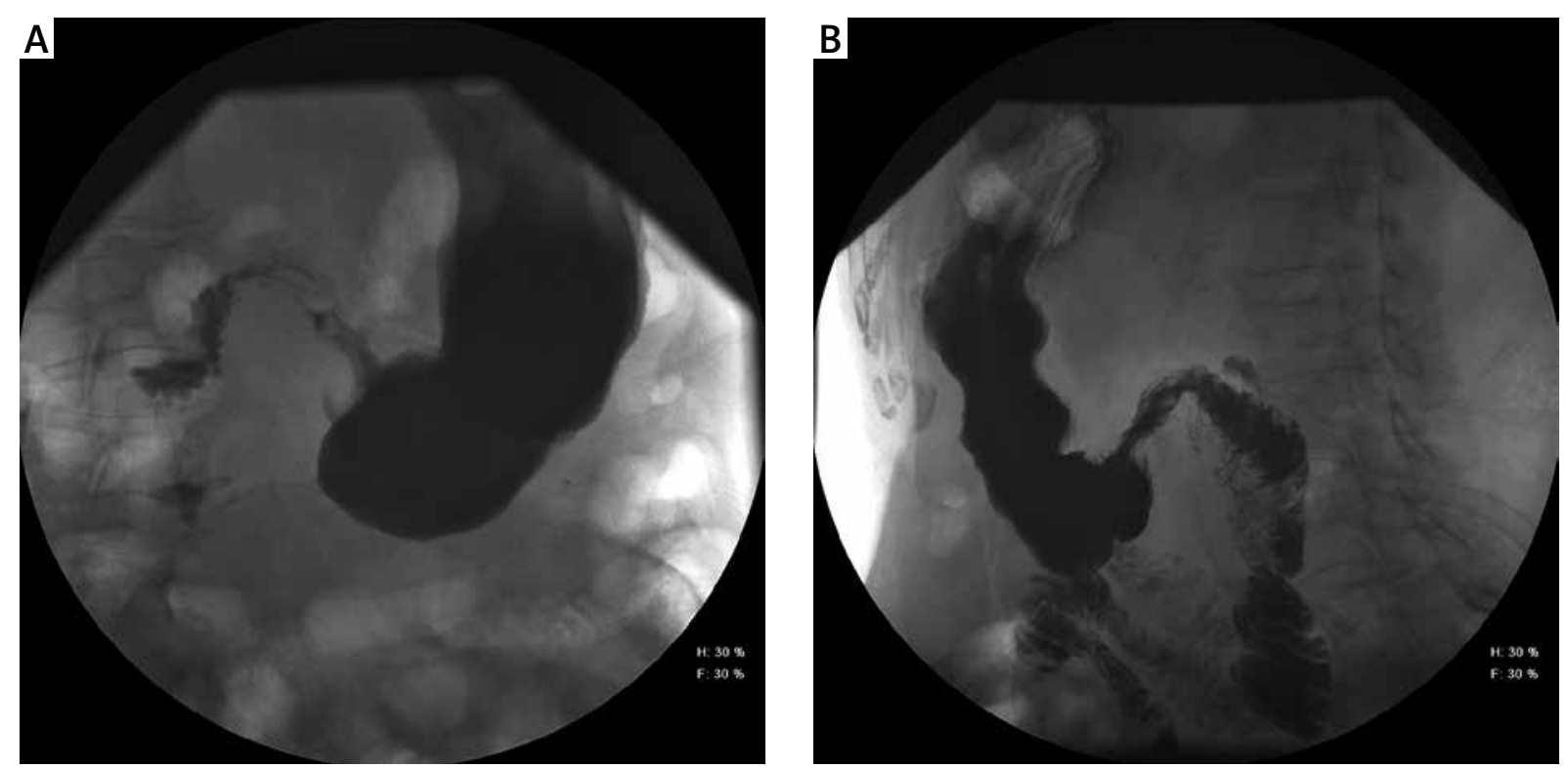

Photos 4 A, B. Gastrografin study showing no sign of anastomotic leakage and no residual stenosis

of PPU was 3.8-14 per 100,000 and the mortality rate was 25\% in 2013 [6]. Although laparoscopic surgery can often be used for differential diagnosis and treatment of suspected acute appendicitis [7], open surgery in PPU emergencies still remains popular due to the lack of laparoscopic experience and less potential harm for the patient or surgical complications. Shock, delayed presentation (> $24 \mathrm{~h}$ ), confounding medical conditions, age > 70 years, American Society of Anesthesiologists class III-IV and Boey score of $\geq 2$ as well as unfavorable ulcer location or large perforation size (> 6-10 $\mathrm{mm}$ ) are considered to be negative factors for laparoscopic repair [8]. Signs of shock are contraindications for the laparoscopic approach to other authors, because of the increase in duration of surgery and the negative influence of pneumoperitoneum on renal function [9]. Laparoscopic repair of PPU has been shown to be safe and effective treatment [10-12]. Budzyński et al. found [9] that laparoscopic surgery was only 21 min longer, with a smaller injury for the patient, and even the presence of shock was not a contraindication for a laparoscopic repair. Laparoscopic repair takes longer, but results in reduced analgesia requirements and better cosmesis [13]. A laparoscopic operation provides an earlier return to normal diet and mobilization, reduced time of staying in hospital and decreased post-operative nasogastric tube duration $[11,14]$. Elderly and frail patients would especially benefit from a minimally invasive procedure in emergencies [15]. Therefore, the laparoscopic approach is preferable to an open operation for patients with PPU.

Laparoscopic emergency pyloroplasty is a difficult procedure, but it may be performed in cases where expertise is available. Further prospective studies are necessary to define the long-term benefits of the laparoscopic procedure. Controversy remains regarding the clinical utility of laparoscopic techniques for the urgent treatment of PPU.

\section{Conclusions}

Laparoscopic emergency pyloroplasty for perforated duodenal ulcer with stenosis may be safely performed. Further studies are necessary to evaluate the feasibility of widespread use of the technique.

\section{Conflict of interest}

The authors declare no conflict of interest.

\section{References}

1. Bertleff MJ, Lange JF. Laparoscopic correction of perforated peptic ulcer: first choice? Surg Endosc 2010; 24: 1231-9.

2. Chey WD, Wong BC; Practice Parameters Committee of the American College of Gastroenterology. American College of Gastroenterology guideline on the management of Helicobacter pylori infection. Am J Gastroenterol 2007; 102: 1808-25.

3. Salomone DS, Bassi M, Smerieri N, et al. Diagnosis and treatment of perforated or bleeding peptic ulcers: 2013 WSES position paper. World J Emerg Surg 2014; 9: 45. 
4. Cellan-Jones CJ. A rapid method of treatment in perforated duodenal ulcer. Br Med J 1929; 1: 1076-77.

5. Moggia E, Athanasopoulos PG, Hadjittofi C, Berti S. Laparoscopic Finney pyloroplasty in the emergency setting: first case report in the literature and technical challenges. Ann Transl Med 2016; 4: 197.

6. Søreide K, Thorsen K, Søreide JA. Strategies to improve the outcome of emergency surgery for perforated peptic ulcer. $\mathrm{Br}$ J Surg 2014; 101: e51-64.

7. Kryzauskas M, Danys D, Poskus T, et al. Is acute appendicitis still misdiagnosed? Open Med (Wars) 2016; 11: 231-6.

8. Lunevicius R, Morkevicius M. Perforated duodenal ulcer: benefits and risks of laparoscopic repair. Medicina 2004; 40: 522-37.

9. Budzyński P, Pędziwiatr M, Grzesiak-Kuik A, et al. Changing pat terns in the surgical treatment of perforated duodenal ulcer single centre experience. Videosurgery Miniinv 2015; 10: 430-6.

10. Lau WY, Leung KL, Kwong KH, etal. A randomized study comparing laparoscopic versus open repair of perforated peptic ulcer using suture or sutureless technique. Ann Surg 1996; 224 131-8.

11. Siu WT, Leong HT, Law BK, et al. Laparoscopic repair for perforated peptic ulcer: a randomized controlled trial. Ann Surg 2002; 235: 313-9.

12. Bertleff MJ, Halm JA, Bemelman WA, et al. Randomized clinical trial of laparoscopic versus open repair of the perforated peptic ulcer: the LAMA Trial. World J Surg 2009; 33: 1368-73.

13. Sanabria A, Morales $\mathrm{CH}$, Villegas $M$, et al. Laparoscopic repair for perforated peptic ulcer disease. Cochrane Database Syst Rev 2005; 4: CD004778.

14. Tan S, Wu G, Zhuang Q, et al. Laparoscopic versus open repair for perforated peptic ulcer: a meta analysis of randomized controlled trials. Int J Surg 2016; 33: 124-32.

15. Michalik M, Dowgiałło-Wnukiewicz N, Lech P, Zacharz K. Surgery of the elderly in emergency room mode. Is there a place for laparoscopy? Videosurgery Miniinv 2017; 12: 115-9.

Received: 9.03.2017, accepted: 21.05.2017 